Validation of Nordic dairy cattle disease recording databases completeness for locomotor disorders

Lind, Ann-Kristina; Thomsen, Peter Thorup; Ersbøll, Annette Kjær; Espetvedt, M. N.; Wolff, C.; Rintakoski, S.; Houe, Hans

Published in:

Preventive Veterinary Medicine

DOI:

10.1016/j.prevetmed.2012.06.009

Publication date:

2012

Document version

Early version, also known as pre-print

Citation for published version (APA):

Lind, A-K., Thomsen, P. T., Ersbøll, A. K., Espetvedt, M. N., Wolff, C., Rintakoski, S., \& Houe, H. (2012).

Validation of Nordic dairy cattle disease recording databases: completeness for locomotor disorders. Preventive Veterinary Medicine, 107(3-4), 204-213. https://doi.org/10.1016/j.prevetmed.2012.06.009 


\title{
Validation of Nordic dairy cattle disease recording databases-Completeness for locomotor disorders
}

\author{
A. Lind ${ }^{\mathrm{a}, *}$, P.T. Thomsen ${ }^{\mathrm{b}}$, A.K. Ersbøll ${ }^{\mathrm{c}}$, M.N. Espetvedt ${ }^{\mathrm{d}}$, C. Wolff $^{\mathrm{e}}$, S. Rintakoski ${ }^{\mathrm{f}}$, \\ H. Houe ${ }^{a}$ \\ a Department of Large Animal Sciences, Faculty of Health and Medical Sciences, University of Copenhagen, Grønnegårdsvej 8, Denmark \\ b Department of Animal Science, Aarhus University, Blichers Allé 20, DK-8830 Tjele, Denmark \\ c National Institute of Public Health, University of Southern Denmark, Øster Farimagsgade 5A, 2, 1353 København K, Denmark \\ d Norwegian School of Veterinary Science, Department of Production Animal Clinical Science, P.O. Box 8146 Dep., NO-0033 Oslo, Norway \\ e Department of Clinical Sciences, Swedish University of Agricultural Sciences, P.O. Box 7054, SE-750 07 Uppsala, Sweden \\ ${ }^{\mathrm{f}}$ Department of Veterinary Biosciences, P.O. Box 66, University of Helsinki, FI-00014, Finland
}

\section{A R T I C L E I N F O}

\section{Article history:}

Received 20 December 2011

Received in revised form 18 May 2012

Accepted 28 June 2012

\section{Keywords:}

Nordic cattle databases

Completeness

Validation

Disease recording

Dairy cows

Locomotor disorders

\begin{abstract}
A B S T R A C T
The Nordic countries Denmark (DK), Finland (FIN), Norway (NO) and Sweden (SE) all have unique national databases holding the disease records of dairy cows. The objective of this study was to estimate and compare completeness for locomotor disorders in the four Nordic national databases. Completeness figures for farmer-recorded disease events were calculated on two different levels: the first refers to disease events that were observed on the farm regardless of whether a veterinarian had been involved (FARMER); the second refers to farmer records of cases attended by a veterinarian, i.e. to veterinarian-treated disease events (VET). A sample of herds with 15 or more cows was obtained from a simple random sample of dairy farms in FIN, NO and SE, and from a systematic random sample in DK. There were 105, 167, 179 and 129 participating farmers in DK, FIN, NO and SE, respectively, and during two 2-month periods in 2008 these farmers recorded the disease events they observed on the farm. Data from the four national databases were extracted in May 2009. The two data sources, farmer recordings and national databases, were managed in a comparable way in all four countries, and common diagnostic codes were created and added to match recordings appearing in both datasets. In all 555 farmers completed data records in the first data-recording period, and 515 farmers did so in the second period. In DK, FIN, NO and SE, 55\%, 77\%, 82\% and 75\%, participating farmers completed the recordings during the first recording period, respectively; the corresponding figures for the second recording period were $71 \%, 82 \%, 83 \%$ and $91 \%$.

To calculate completeness, disease cases recorded in the national databases were compared with the farmer recordings using an exact match for the locomotor complex defined as same country, herd identification number (id), cow id, and event date at the levels of FARMER and VET. Completeness at FARMER level were $0.22,0.21,0.23$ and 0.12 in DK, FIN, NO and SE, respectively. At VET level they were $0.37,0.27,0.34$ and 0.17 . To compare differences in completeness between countries exact $95 \%$ confidence intervals were calculated. There were significant differences in completeness between DK and SE at both FARMER and VET level. The completeness indicate that the ability to estimate true disease occurrences in the four national databases varies and is in general poor. Completeness should be taken into account when disease occurrences in different countries are compared.
\end{abstract}

(c) 2012 Elsevier B.V. All rights reserved.

\footnotetext{
* Corresponding author. Tel.: +46 18671856/707297 400; fax: +46 18673545 .

E-mail address: ann-kristina.lind@slu.se (A. Lind).
} 


\section{Introduction}

Cattle databases in the Nordic countries, Denmark (DK), Finland (FIN), Norway (NO) and Sweden (SE) have long been recognized as comprehensive recording systems of production and disease at the level of the individual animal and the herd. This is reflected in the substantial volume of publications reporting and analyzing data from those databases (e.g. Lindberg et al., 2003; Østerås et al., 2003; Egenvall et al., 2011). The disease recording systems rely on reports of veterinarian-treated disease events (Gröhn et al., 1984; Olsson et al., 2001; Sviland and Waage, 2002). Primary databases often refer to databases that were constructed for a specific research project. Secondary databases were originally constructed for other purposes (Sørensen et al., 1996). The secondary sources are of great value in research. Data from secondary databases need to be studied with considerable care. Nevertheless, the secondary databases can save time and resources (Egenvall et al., 2011; Houe et al., 2011). Although information from secondary databases is used in many studies, few studies have evaluated the quality of the data as such (Egenvall et al., 1998; Penell et al., 2007; Mörk et al., 2009; Penell et al., 2009). Several published papers discuss this problem and identify the need for data in databases used for secondary purposes to be validated (Bartlett et al., 1986; Olsson et al., 2001). Only a few validation studies have been carried out looking at disease databases in the Nordic countries (Bennedsgaard, 2003; Gulliksen et al., 2009; Mörk et al., 2009, 2010). Obviously, the successful validation of such the databases would help to demonstrate that their data can be used safely in future research, assuming the validity remains constant over time for each diagnosis (Houe et al., 2011).

Detailed data recording in the Nordic countries permits the incidence of disease in countries in the region to be compared. The first attempt to compare disease occurrences in different Nordic countries was made in 1993 (Plym-Forshell et al., 1995). In 2003 a pilot project was established with the aim of comparing disease incidences (Østerås et al., 2002), and in particular comparing the incidence of bovine mastitis in Denmark (DK), Finland (FIN), Norway (NO) and Sweden (SE) (Valde et al., 2004). Results from these studies showed that the comparison of data from these countries is far from straightforward, even if one has unimpeded access to database records in all four countries. In connection with human medical records, differences between countries with implications for the comparison of database data have been addressed. The difficulties combining studies from different countries are largely due to contrasts in coding practice and computer systems (Jordan et al., 2004). The comparison of data raises many questions. For example, issues arise concerning such matters as raw data management, the dangers in different databases of data loss and data errors that are not properly taken into account, and the possibility that the sampling criteria may differ between the countries' databases.

In 2007, a Nordic research collaboration project called the Dairy Health Recording Validity Assessment
(DAHREVA) was set up with the aim of validating disease records in the national databases for dairy cows in DK, FIN, NO and SE. The project aims to validate dairy cow databases simultaneously, in a comparable way. The specific objectives of the work presented in this paper were to estimate and compare completeness (e.g. how well the occurrence of locomotor disorders on the farm is captured) in the Nordic countries' cattle disease databases.

\section{Materials and methods}

\subsection{Selection of herds and cows}

The target population in this study was dairy cows that were from herds of at least 15 cows at the time of data sampling in DK, FIN, NO and SE. The herds in DK, NO and SE participated in the milk yield control, and the herds in FIN participated in the health surveillance system. To emphasize, the purpose of the database is the same. "ND" is one part of the milk yield control or health surveillance system and that in all countries the database is designed to capture all medically treated animals and not all sick animal. Initially a number of herds were selected at random. After selection, all cows were observed for 4 months. Finally, herds that reported any disease events on the farm were selected for the study.

Sample size was calculated based on national disease incidences from the previous years, the herd size, and assuming a sensitivity/completeness of $80 \%$ and the ability to detect this level of data loss with $95 \%$ confidence. For further explanations, see Espetvedt et al. (2012).

In January 2008 random samples of $1000,900,800$, and 400 farmers in DK, FIN, NO and SE, respectively, received an invitation to participate in the project by standard mail. The number of invited herds was different for each country. FIN, NO and SE sent invitation letters earlier than DK. Following a low initial response rate, FIN and NO sent another invitation, telephoned the farmers not responding to the invitation letter in the first batch, and just accepted the 'yes'-answers in the second batch. SE sent one invitation and then telephoned nonresponders until a sufficient number of herds had been recruited. DK sent their first invitations at the same time as FIN and NO sent their second invitations. Aware of the low response rates in other countries, DK contacted more farmers initially and telephoned farmers who replied that they might want to participate. The sampling frame involving herds of at least 15 cows from the four national databases. In DK 3980 were in the sample frame of a total of 4002 herds in the control year 2007/2008. In FIN the sampling frame consisted of 8725 herds in the Finnish Agricultural Data Processing Centre out of a total of 12,455 herds in 2008 . The sampling frame for NO was 7489 herds in the Norwegian Dairy Herd Recording System out of a total of 14,182 herds in 2006. In SE the sampling frame was 5094 herds out of a total of 6573 dairy herds in 2008 . 


\subsection{Study design}

The study was an observational cross-sectional study modified so that the data were sampled during two 2month periods in 2008. The study periods were in early spring and late autumn to avoid busy times during seeding and harvest. Earlier study by Mörk et al. (2009) found no seasonal differences in completeness in SE. Information and registration sheets for the recording of observed diseases in cows were sent to farmers a couple of days before the start of the study. Reminders were sent out after a month and at the end of both periods either by phone, or by standard mail, email or Short Message Service, prompting the farmers to return the recording sheets. Before the second 2-month period an information letter was sent to all participating farmers briefly describing the results from the first study period. At the end of the second study period, another letter was sent thanking the farmers for participating and reminding them to return the registration sheets.

The study required close collaboration between principal investigators in the four countries. Various measures helped to ensure consistency in the filling out of the recording sheets: these related to the design of the recording sheet, the instructions provided and consistent followup with participating farmers. The recording sheet had a basic design, with the most common diseases pre-printed. Considerable efforts were made to issue clear instructions to the farmers on how to fill in the recording sheet. These instructions were clearly printed on the back of each recording sheet. The farmers were also provided with an example of a filled-in recording sheet. All documents were written in English before being translated into native languages, and the translations were checked by the appropriate members in the research group.

Recording of disease treatments is mandatory in DK. The veterinarian or the farmer must submit the record of a disease treatment to the central database. It is voluntary to participate in milk recording however most Danish farmers do (Personal communications, Danish Cattle). In FIN, recording diseases to the database is voluntary, although book-keeping on medication used on the farm is mandatory. Each cow has a health card, where the veterinarian records disease treatments. The farmer or, most commonly, the artificial insemination technician submits the information to the national database. In NO, all cows have a health card and it is mandatory to record disease on the health card regardless of whether the cow diagnosed with a disease was treated or not. It is the farmer's responsibility that the health card gets filled in by the veterinarian. For herd $s$ participating in milk recording the farmer or the herd advisor must submit the information in the health cards to the national database. Since 2004, a special health card is used for recording claw disorders in NO (Anonymous, 2008). In SE, book-keeping on medication on the farm is mandatory. Veterinarians should write a record regardless of whether the cow diagnosed with a disease was treated or not. The veterinarian must submit the record to the Board of Agriculture. If the herd participates in milk recording the information is subsequently transferred by the Swedish Board of Agriculture to the Swedish Dairy Association's cattle database. Details regarding the national recording systems have been published in earlier studies (Gröhn et al., 1986; Bartlett et al., 2001; Olsson et al., 2001; Østerås et al., 2007; Mörk et al., 2010).

In DK farmers can participate in three kinds of herd health contract system: the 'Core' agreement, the 'Module1' agreement and the 'Module2' agreement. In the Core agreement veterinarians initialize treatment and administer the follow-up treatments as well. In the Module 1 agreement veterinarians initialize treatment, but farmers are allowed to re-treat the animal for up to five days. In the Module 2 agreement farmers are allowed to initialize treatments and the veterinarian makes frequent scheduled visits (Anonymous, 2010).

\subsection{Farmers' disease recording (FR)}

The farmers were asked to record clinical disease. By 'farmer' we mean the animal caretaker or the person responsible for the daily supervision of the lactating cows on the farm. This means that the farmers should record what they observed as abnormal during their routines and includes both veterinary and non-veterinary treated events. Thus 'farmer observed' includes both veterinarian and non-veterinarian treated events. The farmers were asked to complete a new recording sheet for each cow whenever they noted a new case of disease, and to add information about the case - e.g. whether the veterinarian had been contacted more than once for the same disease in that cow - on the same sheet.

The farmers' observations were recorded on a purposemade recording sheet on which diseases were precategorized into four major disease complexes: locomotor disorders, udder disorders, metabolic disorders and reproductive disorders. Space was available to state if any diseases that did not fall into one of these four categories were observed. In each disease category the farmers had the option of noting clinical signs and diagnoses, and of noting any treatments undertaken by themselves, the veterinarian or the hoof trimmer. Farmers were also told to record any episodes of sudden death, or deaths related to the recorded disease. On request, a copy of the recording sheet is available from the first author, either in English or any of the four Nordic languages. The participating farmers were able to submit their recordings electronically, by fax or by standard mail.

\subsection{Variables from the national databases (ND)}

The data extracted from the national databases covered the period from January 2007 to May 2009. May 2009 was selected in order to ensure that as much data had been entered as possible, given the potential delays in registrations into the national databases. The data contained information on herd characteristics (herd ID, and housing systems) and individual cows (cow identification number, disease events, breed, sex, day of entry into the herd, date of exit from the herd, culling reasons and methods, date of birth, test milking results, lactation number, inseminations and calvings). 
Table 1

Establishment of common disease categories for locomotor disorders based on individual diagnostic code labels obtained from National dairy disease databases in Denmark, Finland, Norway and Sweden.

\begin{tabular}{|c|c|c|c|c|}
\hline \multirow{2}{*}{$\begin{array}{l}\text { Common categories } \\
\text { established }^{\mathrm{a}}\end{array}$} & \multicolumn{4}{|c|}{ Individual diagnostic code labels used in the 4 Nordic countries ${ }^{b}$} \\
\hline & Denmark & Finland & Norway & Sweden \\
\hline Arthritis & Arthritis & $\begin{array}{l}\text { Arthritis periarticular } \\
\text { infection } \\
\text { Hoof trimmer's codes: } \\
\text { Periarticular infection }\end{array}$ & Arthritis & $\begin{array}{l}\text { Swollen joint; Increased amount of } \\
\text { synovia (in joint) Infectious, } \\
\text { inflammatory process in joint; } \\
\text { Arthritis (2 codes 9909/10707); } \\
\text { Acute arthritis; Acute } \\
\text { serous/serofibrinous arthritis; } \\
\text { Acute synovitis; Acute purulent } \\
\text { arthritis ( } 2 \text { codes 9914/9915); } \\
\text { Acute septic arthritis; } \\
\text { Serous/serofibrinous arthritis; } \\
\text { Synovitis; Chronic arthritis; } \\
\text { Purulent arthritis; Chronic } \\
\text { purulent arthritis; Chronic septic } \\
\text { arthritis; Septic arthritis }\end{array}$ \\
\hline Laminitis & $\begin{array}{l}\text { Laminitis; Laminitis red } \\
\text { sole; Laminitis red sole } \\
\text { white line; Laminitis broad } \\
\text { white line }\end{array}$ & $\begin{array}{l}\text { Acute laminitis; } \\
\text { Chronic laminitis; } \\
\text { Subclinical laminitis } \\
\text { Hoof trimmer's codes: } \\
\text { Chronic laminitis }\end{array}$ & Laminitis & $\begin{array}{l}\text { Metabolic changes, hoof; } \\
\text { Laminitis; Acute laminitis; } \\
\text { Laminitis at partus; Laminitis } \\
\text { caused by over exercise; Chronic } \\
\text { laminitis; Lowering, rotation of 3rd } \\
\text { phalangeal bone }\end{array}$ \\
\hline Dermatitis & $\begin{array}{l}\text { Digital dermatitis, } \\
\text { Interdigital phlegmon; } \\
\text { Interdigital dermatitis; } \\
\text { Interdigital hyperplasia } \\
\text { (fibroma); Interdigital } \\
\text { dermatitis; Interdigital } \\
\text { hyperplasia, side; } \\
\text { Interdigital hyperplasia, } \\
\text { middle }\end{array}$ & $\begin{array}{l}\text { Interdigital dermatitis, } \\
\text { Heel erosion, Rot of the } \\
\text { white line } \\
\text { Hoof trimmer's codes: } \\
\text { Heel erosion; White } \\
\text { line disease; } \\
\text { Interdigital dermatitis }\end{array}$ & $\begin{array}{l}\text { Dermatitis; Interdigital } \\
\text { dermatitis (phlegmon } \\
\text { interdigital, cellulitis) }\end{array}$ & $\begin{array}{l}\text { Digital dermatitis; Cellulitis hoof, } \\
\text { claw; Cellulitis, hoof; Verrucous } \\
\text { dermatitis. Interdigital } \\
\text { inflammation, panaritium; } \\
\text { Interdigital excema; Interdigital } \\
\text { dermatitis }\end{array}$ \\
\hline $\begin{array}{l}\text { Hoof abscess/ } \\
\text { sole ulcer }\end{array}$ & $\begin{array}{l}\text { Sole ulcer; Sole ulcer } \\
\text { slight; Sole ulcer bandage; } \\
\text { Sole ulcer double sole; } \\
\text { White line disease }\end{array}$ & $\begin{array}{l}\text { Sole ulcer: Hoof } \\
\text { trimmer's codes: Sole } \\
\text { hemorrhages; Sole } \\
\text { ulcer }\end{array}$ & $\begin{array}{l}\text { Sole bruising; White } \\
\text { line abscess/disruption }\end{array}$ & $\begin{array}{l}\text { Pododermatitis circumscripta; Sole } \\
\text { bruising; Heel horn erosion; Hoof } \\
\text { abscess; Abscess/fistula hoof, claw; } \\
\text { Abscess/fistula hoof }\end{array}$ \\
\hline
\end{tabular}

\footnotetext{
a Not presented here was the 'lameness other' category that included 6, 10, 10 and 217 different locomotor codes from Denmark, Finland, Norway and Sweden, respectively.

b The diagnostic code labels are separated with semicolon in the table, and every new code label starts with a capital letter.
}

\subsection{Disease coding}

Each of the four national databases has its own coding system for diseases, and there is variation in the databases in respect of how specific the codes are. Table 1 shows how codes from the four databases were combined to represent locomotor diagnostic events.

$\mathrm{SE}$ is the country with the largest number of, and most specific, diagnostic codes. In SE more than 4000 codes are used when veterinarians report diseases to the Swedish Board of Agriculture. By comparison, DK has 214 diagnostic codes for veterinarians to use when reporting diseases to the DCD. In the locomotor category 5 diagnoses were pre-printed on the recording sheet for the farmer to choose between, namely: arthritis, laminitis, dermatitis, hoof abscess/sole ulcer and lameness other. The diagnosis 'arthritis' corresponds in the national database to 1 diagnostic code in DK and NO, 3 codes in FIN and 12 codes in $\mathrm{SE}$. The numbers of specific diagnoses in the four countries for other locomotor disorders were as follows: 'dermatitis' 7, 2, 2 and 6; 'laminitis' 4, 3, 1 and 7; 'hoof abscess/sole ulcer' 5, 1, 2 and 6 (Table 1); and 'lameness other' 6, 10, 10 and 217 , respectively.

\subsection{Representativeness}

Confidence intervals for the study herds in DK, FIN, NO and SE were compared with the national herds in the milk recording scheme in respect of herd size, \%-fat, \%-protein, mean energy corrected milk yield per cow and average bulk tank somatic cell count. Summary statistics on all Danish dairy herds originated from the Danish Cattle Federation (Anonymous, 2009). Information on the Finnish, Norwegian and Swedish dairy herds originated from the Finnish Agricultural Data Processing Centre, TINE SA (the Norwegian Dairy Association) and the Swedish Dairy Association.

\subsection{Data management and data control}

The disease registration sheets were scanned in NO. In FIN they were partly scanned and partly entered manually. In DK and SE all sheets were entered manually. All recordings were proof-read and checked using common guidelines in all four Nordic countries.

All data management, data control and analyses were performed using SAS version 9.2 (SAS Institute Inc., Cary, NC, USA). Unknown herd or cow identifications and farmer 
Table 2

A 2 by 2 table illustrating how recordings in a national database (ND) is compared to recordings by the farmer (FR). The table is used to calculate completeness of ND recordings as compared to FR recordings.

\begin{tabular}{llll}
\hline & FR+ & FR - & Total \\
\hline ND+ & $\mathrm{a}(\mathrm{FR}+/ \mathrm{ND}+)$ & $\mathrm{b}(\mathrm{FR}-/ \mathrm{ND}+)$ & $\mathrm{a}+\mathrm{b}$ \\
$\mathrm{ND}-$ & $\mathrm{c}(\mathrm{FR}+/ \mathrm{ND}-)$ & $\mathrm{d}^{\mathrm{a}}(\mathrm{FR}-/ \mathrm{ND}-)$ & $\mathrm{c}+\mathrm{d}$ \\
Total & $\mathrm{a}+\mathrm{c}$ & $\mathrm{b}+\mathrm{d}$ & \\
\hline
\end{tabular}

a d not possible to assess.

observations recorded outside the study period for both FR and ND were deleted. In addition, heifers, calves and bulls were removed. Hoof-trimmer data were present in all four national databases. However, since the farmer was not asked to record subclinical locomotor disorders, these hoof-trimmer observations were deleted from the sample. The farmer was asked to fill in one recording sheet for each event, but in DK if any re-treatments (e.g. antibiotics) were given to the specific cow, farmers were asked to register every single day the cow received the treatment with ND. This meant that disease recordings in the national databases relating to the same cow and the same diagnosis within 8 days were categorized as one locomotor case.

\subsection{Data analysis}

Completeness figures were calculated at two different levels to make country-wise comparisons and validation of four national databases' ability to reflect disease occurrences on farms. The term completeness refers to the probability of a disease event being recorded into the databases.

\subsection{Reference levels}

F1: The reference level was the farmer recordings during the two 2-month periods, FR+ (Table 2).

F2: The adjusted reference level was the farmer-recorded disease occurrences $(\mathrm{FR}+)$ with the non-farmer reported cases that were recorded in the national databases (FR-/ND+) added (Table 3). The F2 was introduced because, if the disease was recorded in the ND but not by the farmer, then the farmer would at least have observed the disease. In such case the farmer has simply failed to record the data on the special recording sheet for the purpose of this study but standard reporting to the national database has been carried out. When farmers

Table 3

A 2 by 2 table illustrating how completeness calculations were adjusted with locomotors cases unreported by the farmer but recorded in the national database (ND). Recordings in ND were compared to recordings by the farmer (FR).

\begin{tabular}{llll}
\hline & FR+ with FR-/ND+ added & FR - & Total \\
\hline ND+ & $\mathrm{a}+\mathrm{b}$ & $\mathrm{b}$ & $\mathrm{a}+\mathrm{b}$ \\
ND- & $\mathrm{c}$ & $\mathrm{d}^{\mathrm{a}}$ & $\mathrm{c}+\mathrm{d}$ \\
Total & $\mathrm{a}+\mathrm{b}+\mathrm{c}$ & $\mathrm{b}+\mathrm{d}$ & \\
\hline
\end{tabular}

a $\mathrm{d}$ not possible to assess. failed to record on the purposed made recording sheet the suspicion that there were even more events on farm (nonveterinarian treated events) that was not recorded on our recording sheet.

\subsection{Match}

Within each country, exact match was defined as a match between ND and FR for the same country, herd identification, cow identification, and date of event calculated for the locomotor complex together.

\subsection{Farmer recorded and veterinary recorded disease events}

FARMER: All farmer-recorded disease events for dairy cows both veterinarian treated and non-veterinarian treated events (excluded those treated by hoof-trimmer) during the two 2-month periods on a purpose-made recording sheet.

VET: Farmer recorded disease events during the two 2month periods where the farmer had indicated that a veterinarian had attended the case.

The non-adjusted completeness (Table 2) used F1, and the adjusted completeness (Table 3 ) used F2.

Completeness was calculated as:

Se $=\operatorname{Pr}\{T+\mid D+\}=\frac{a}{a+c}$

The adjusted completeness was calculated as:

Se $=\operatorname{Pr}\{T+\mid D+\}=\frac{a+b}{a+b+c}$

where $T+$ is disease events recorded in the 'national' database and $D+$ is all events observed by the farmer on either FARMER or VET level, and $a / b / c / d$ are as defined in Table 2.

Exact confidence intervals $(\mathrm{CI})$ for the completeness at 95\% significance level were calculated (Casella and Berger, 1990). Country-specific completeness were compared and classified as significantly different if the CIs were nonoverlapping.

\section{Results}

\subsection{Descriptive statistics for response rate and disease recordings}

In total 105, 167, 179 and 129 herds in DK, FIN, NO and SE, respectively, were involved in completing data recording (Table 4 ). Of farmers initially agreeing to participate, $55 \%, 77 \%, 82 \%$ and $75 \%$, completed the first recording period, while $71 \%, 82 \%, 83 \%$ and $91 \%$ completed the second recording period in DK, FIN, NO and SE, respectively.

In FR $2280_{\mathrm{DK}}, 1403_{\mathrm{FIN}}, 887_{\mathrm{NO}}$ and $1178_{\mathrm{SE}}$ disease recording events were obtained, and the numbers of farmer-recorded locomotor disorders were 426, 147, 97 and 193, from DK, FIN, NO and SE, respectively (Table 4). Altogether 448 (7.1\%) recordings were removed from the sample for various reasons: event outside the study period, 
Table 4

Descriptive statistics of the herds and disease data recorded by farmers in the four Nordic countries during two 2-month periods in 2008. Completeness of disease recordings were calculated for registrations obtained in the four Nordic national dairy cattle databases, compared to farmer recorded locomotor disorders.

\begin{tabular}{|c|c|c|c|c|}
\hline & Denmark & Finland & Norway & Sweden \\
\hline Number of participating herds & 105 & 167 & 179 & 129 \\
\hline Average herd-size & 109 & 32 & 27 & 59 \\
\hline Number of farmer-recorded disease events & 2280 & 1403 & 887 & 1178 \\
\hline Number of cows in the study & 11445 & 5344 & 4833 & 7611 \\
\hline Number of disease events per 100 cows & 19.9 & 26.3 & 18.4 & 15.5 \\
\hline Number of farmer-recorded locomotor disorders (\% veterinarian-visited) & $426(64)$ & $147(75)$ & $97(68)$ & $193(73)$ \\
\hline Number of locomotor disorders per 100 cows & 3.28 & 2.87 & 2.14 & 2.54 \\
\hline
\end{tabular}

no dates given for the event, cow identification number not recorded, herd identification number not found in the national database, duplicate recording of disease event, recording from heifers before their first calving, and recording from male animals.

\subsection{Completeness}

Completeness figures of the locomotor complex for an exact match were calculated both at the FARMER level and VET level. The completeness were low for locomotor disorders ranging from $12 \%$ in SE to $23 \%$ in FIN at FARMER level, and from $17 \%$ in SE to $37 \%$ in DK at VET level, when calculating F1. In general, completeness increased in all countries at VET level when compared with FARMER level (Tables 5 and 6). Overall DK data had the highest completeness, and SE the lowest, for locomotor disorders at both FARMER and VET level. When completeness were calculated using F2, the completeness increased for all four countries (Table 5). There were significant differences in completeness for disease recordings of locomotor disorders, both at FARMER and VET level, between DK and SE. When VET level was used the completeness in FIN and SE were significantly different.

\subsection{Representativeness of study herds}

There were only small differences in the variables (herd size, \%-fat, \%-protein, mean energy corrected milk yield and bulk milk somatic cell count) assessed for representativeness between the study herds and (a) all herds participating in milk recording for DK and (b) all herds participating in milk recording with at least 15 cows on average per year in FIN, NO and SE (Table 7). Only in FIN did the study herds have higher average milk yield than the target herds when the confidence intervals were compared. In DK average herd size was smaller in the study herds than it was in all herds in DK. Herd size was slightly larger in the study herds than it was in the target herds in FIN, NO and SE (Table 7), but the differences were not statistically significant.

\section{Discussion}

\subsection{Comparison of completeness}

The completeness of the disease recording systems in the Nordic countries, and specifically their ability to correctly identify cases of locomotor disorders, were low. The completeness at VET level was higher than it was at FARMER level-as might well be expected, since veterinarian-treated animals should end up providing records for national databases. Given the design of the disease recording systems in Nordic countries, the completeness of veterinarian-treated data should be $100 \%$. However, the low completeness obtained for locomotor disorders shows that this is not the case. There can be several reasons for the low completeness obtained for locomotor disorders, e.g. the facts that it is not mandatory to record disease that are not veterinarian treated and hoof trimmer are an example of treatment the farmers might do themselves. Such cases can explain that there are more diseases on farm than recorded in the databases and therefore completeness figures for the VET level is higher than for the FARMER level. However, in a well-functioning system the completeness for the VET level as mentioned should approach $100 \%$. Earlier studies by Bennedsgaard

\section{Table 5}

Completeness figures with confidence intervals (CI) calculated for farmer-recorded (FR) locomotor cases compared with locomotor recordings obtained in the four Nordic national dairy cattle databases (ND) are presented. The completeness figures are calculated for the reference level (F1) and the adjusted reference level (F2) where non-recorded farmer cases but recorded in ND is added. The locomotor cases in FR were compared with locomotor cases in ND for a match for same country, same herd id, same cow id, exact date and for locomotor complex. The locomotor complex contains five different locomotor categories: arthritis, laminitis, dermatitis, hoof abscess/sole ulcer and lameness other. The study was performed in two 2-month periods in 2008 in Denmark, Finland, Norway and Sweden.

\begin{tabular}{llllr}
\hline \multirow{2}{*}{ Country } & \multicolumn{2}{l}{ F1 - farmer recording } & & \multicolumn{2}{c}{ F2 - adjusted farmer recording } \\
\cline { 2 - 3 } & Total events FR & Completeness $(\mathrm{CI})$ & & Total events (FR+)+(FR-/ND+) \\
\hline Denmark & 408 & $0.22(0.18 ; 0.27)$ & 578 & 169 \\
Finland & 140 & $0.21(0.15 ; 0.28)$ & $0.45(0.28 ; 0.63)$ \\
Norway & 78 & $0.23(0.15 ; 0.34)$ & $0.35(0.28 ; 0.42)$ \\
Sweden & 187 & $0.12(0.08 ; 0.18)$ & 204 & $0.30(0.22 ; 0.41)$ \\
\hline
\end{tabular}


Table 6

Completeness figures with confidence intervals (CI) calculated for farmer-recorded (FR) locomotor cases attended by a veterinarian compared with locomotor recordings obtained in the four Nordic national dairy cattle databases (ND) are presented. Completeness are both calculated for the reference level (F1) and the adjusted reference level (F2) where non-recorded farmer cases but recorded in ND is added. The locomotor cases in FR were compared with locomotor cases in ND for a match for same country, same herd id, same cow id, exact date and for locomotor complex. The locomotor complex contains five different locomotor categories; arthritis, laminitis, dermatitis, hoof abscess/sole ulcer and lameness other. The study was performed in two 2-month periods in 2008 in Denmark, Finland, Norway and Sweden.

\begin{tabular}{llllr}
\hline & \multicolumn{2}{l}{ F1 - veterinarian-attended } & & \multicolumn{2}{c}{ F2 - adjusted veterinarian-attended } \\
\cline { 2 - 3 } Country & Total events FR & Completeness $(\mathrm{CI})$ & & Total events (FR+)+(FR-/ND+) \\
\hline Denmark & 235 & $0.37(0.30 ; 0.43)$ & 405 \\
Finland & 105 & $0.27(0.19 ; 0.36)$ & 135 & $6.64(0.19 ; 0.93)$ \\
Norway & 53 & $0.34(0.23 ; 0.47)$ & $0.43(0.35 ; 0.51)$ \\
Sweden & 136 & $0.17(0.12 ; 0.24)$ & $0.43(0.31 ; 0.55)$ \\
\hline
\end{tabular}

(2003) and Mörk et al. (2010) have addressed that this is not the case and found that around $20-30 \%$ of the data were lost. Thus the low completeness are comparable with earlier findings by Lindberg et al. (2003), who obtained completeness with mean values of $0.15,0.12$, 0.0090 and 0.19 for locomotor disorders in DK, FIN, NO and SE, respectively. These completeness figures are even lower than those found in the present study. This might be explained by differences in the management of the data and in methods of calculation: Lindberg and her colleagues used simulation sampling, while our study was based on farmer observations. However, it remains true that both results indicate low completeness for locomotor disorders. Similar results were obtained for calf and young stock in a Norwegian project, about diseases in calves where Gulliksen et al. (2009) found that approximately $40 \%$ of locomotor recordings were missing. Comparing with other diseases recorded in the national databases, completeness of database recording for locomotor disorders as a measure for disease occurrence is low. Low completeness figures for the FARMER level are not necessary bad because the Nordic databases are made for capturing treatments. There can be several reasons for the low completeness obtained for locomotor disorders, e.g. the facts that it is not mandatory to record disease that are not veterinary treated and hoof trimming is an example of treatment the farmers might do themselves. Such cases can explain that there are more diseases on farm than recorded in the databases and therefore completeness figures for the VET level is higher than for the FARMER level. However, in a well-functioning system, the completeness figures for the VET level should approach $100 \%$ since such record should be recorded in the four national databases. Earlier studies by Bennedsgaard (2003) and Mörk et al. (2010) have addressed that this is not the case and found that around $20-30 \%$ of the data are lost in the data transferring process. Other completeness figures for data validation in the Nordic countries have been carried out for metabolic disorders and Espetvedt et al. (2012) found completeness figures for milk fever to be $0.88,0.71,0.80$ and 0.82 in DK, FIN, NO and SE respectively. The reason why the completeness figures for locomotor disorders obtained in this study differs so much compared to, e.g. milk fever could be due to the fact that no discrepancy in date were allowed for locomotor disorders as compared to milk fever and this can have quite an impact for the completeness. When comparing F1 and F2 the completeness figures increases in all four countries both for FARMER and VET level. Small differences between F1 and F2 may indicate god farmer recordings whereas big differences could indicate poor farmer recordings. In the study by Lindberg et al. (2003), they found higher completeness for mastitis, metabolic diseases and reproduction diseases compared to locomotor disorders. These diseases have a longer tradition of being recorded; traditionally they have been regarded as diseases of greater importance than locomotor diseases. To improve the system, much greater attention should be given to locomotor disorders.

Table 7

For comparison of representativeness of the study herds (herds with more than 15 cows per year), descriptive statistics (means ( $95 \%$ confidence intervals)) are shown. In Denmark the study herds were compared with the average of all Danish dairy herds participating in milk recording in 2008. In Finland, Norway and Sweden the study population were compared with target population (herds participating in milk recording with more than 15 cows per year). The results shown are not strictly comparable between the countries.

\begin{tabular}{|c|c|c|c|c|c|c|}
\hline Country & & Herd-size & Fat $\%$ & Protein \% & $\begin{array}{l}\text { Mean energy corrected } \\
\text { milk yield per cow (kg) }\end{array}$ & $\begin{array}{l}\text { Average bulk tank } \\
\text { somatic cell count } \\
\text { (1000 cells) }\end{array}$ \\
\hline \multirow[t]{2}{*}{ Denmark } & Study herd & $108.7(96.7 ; 120.8)$ & $4.41(4.29 ; 4.53)$ & $3.47(3.42 ; 3.53)$ & $8914.31(8674 ; 9155)$ & $241.3(229.7 ; 253.0)$ \\
\hline & All herds ${ }^{a}$ & 126.3 & 4.26 & 3.41 & 8922 & 244.5 \\
\hline \multirow[t]{2}{*}{ Finland } & Study herd & $31.7(29.1 ; 34.4)$ & $4.18(4.12 ; 4.23)$ & $3.44(3.42 ; 3.46)$ & $8973.7(8809 ; 9138)$ & $167.6(153 ; 183)$ \\
\hline & Target herds & $30.7(30.3 ; 31.2)$ & $4.20(4.19 ; 4.21)$ & $3.42(3.42 ; 3.43)$ & $8689.4(8661 ; 8718)$ & $169.7(168 ; 172)$ \\
\hline \multirow[t]{2}{*}{ Norway } & Study herd & $26.7(24.3 ; 29.1)$ & $4.2(4.14 ; 4.26)$ & $3.4(3.39 ; 3.42)$ & $7109(6967 ; 7251)$ & $130(124 ; 135)$ \\
\hline & Target herds & $25.3(24.97 ; 25.5)$ & $4.21(4.19,4.22)$ & $3.39(3.39,3.40)$ & $6978(6954 ; 7001)$ & $134(133 ; 135)$ \\
\hline \multirow[t]{2}{*}{ Sweden } & Study herd & $59.1(51.6 ; 64.4)$ & $4.19(4.16 ; 4.24)$ & $3.42(3.40 ; 3.44)$ & $9172.6(9119 ; 9521)$ & $235.5(222 ; 256)$ \\
\hline & Target herds & $58.7(57.7 ; 60.3)$ & $4.20(4.18 ; 4.20)$ & $3.42(3.41 ; 3.42)$ & $9319.8(9138 ; 9280)$ & $239.3(233 ; 237)$ \\
\hline
\end{tabular}

\footnotetext{
a Data on all Danish dairy herds are from Anonymous (2009).
} 
Removal of records provided by hoof trimmers from the data had a substantial impact on the Swedish data received from ND, although only a few herds in SE contributed a high number of hoof-trimmer records. The data decreased to 41 observations in ND, as compared with the 1911 observations with hoof-trimmer data. The hoof-trimmers do not give medical treatment and it is voluntarily to record hooftrimmer data to ND only veterinary treated events must be recorded. The main reason why hoof trimmer data should not be included is that the ND is not meant to capture it like medical treatments. Further, farmers were asked to record cows with clinical signs not subclinical diseases, whereas hoof-trimmer registrations included the latter, removal of hoof-trimmer data would offer maximum completeness in database estimates of disease status. Retention of the hooftrimmer data would have led to an overestimation of the number of ND cases and, hence, higher completeness in all countries, and especially SE, when adjustments for the cases not reported by the farmer but recorded in ND had been made.

The farmers have different threshold for discovering a diseased dairy cow and different criteria's of how to make the decision about to treat the cow or not. The thresholds and criteria may vary both between different farms and also between farmers and herdsmen working at the same farm. In addition, there are factors at the cow level (lactation stage, lactation number, economic value, age, etc.), changes in cost of treatment, the actual bulk milk somatic cell count status on the farm, the milk prices, former experiences with treatments or differences between organic and conventional farmers, which the farmer could consider (Vaarst et al., 2002). Such factors therefore play an obvious role in the criteria for deciding upon treatment.

The criteria for distinguishing between different diagnosis and at what level of detail the diagnoses is made (e.g. lame or swollen hock) also varies between farms and also within a farm with more than one animal caretaker. The Nordic databases are not meant to record all disease events on farm but only treatment events. The quality (or thoroughness) of registration is also an issue. A wrong disease code or animal identification can be recorded and other entering mistakes can be added. Some farmers are keen on alternative treatments as homeopathy and these treatments are often not recorded in the database.'

Locomotor disorders may be treated by the farmer or may go undetected. Farmers' management and behavior is important for obtaining locomotor disorders. Especially detection and notification are steps in the data flow from a disease event to a record in the database that have a great influence of what frequency of locomotor disorders that is obtained. The VET level is visited by veterinarians and should therefore be recorded in the databases but still the completeness obtained for the locomotor disorders are low.

In this study completeness were calculated for two different reference levels standards: F1 and F2. The F2 adjustment is judged a better reference level, since a record obtained in ND means that the farmer should at least have observed the animal, even if he or she forgot, or chose not, to report it in FR. Previous studies of validation have suggested that an overall completeness of $90 \%$ in a disease database should be regarded as high, that $80-89 \%$ should be regarded as fair, and that $70 \%$ and below should be regarded as poor (Egenvall et al., 1998; Jordan et al., 2004). By these measures, the completeness for locomotor disorders in all four Nordic dairy cattle databases is poor.

\subsection{Other studies of data validation}

There is a clear need for validation studies of disease records across countries. To our knowledge no studies, other than the present one, have been published on the between-country validation of animal databases. A Swedish study (Mörk et al., 2009) found an overall completeness of $73 \%$ for all diagnostic codes in the Swedish national database. Bennedsgaard (2003) studied the completeness of the Danish recording system. Validation of the DCD was carried out by comparing recordings in DCD from 87 herds with copies of withdrawal notes, cow files or veterinarians' diaries from herds and veterinary practices. During the years $1999-2000,19-21 \%$ of the data were missing in DCD.

\subsection{Data management and methodology}

It is very difficult to compare disease status from one country to another, because countries have very different systems of coding. The general and most common diagnoses in dairy cows (e.g. mastitis, milk fever, retained placenta, laminitis) are coded in the four national databases, but there are differences in the specificity of these diagnoses. The common diagnostic codes were a mixture of more or less specific diagnoses obtained from the four national databases. Earlier studies (e.g. Valde et al., 2004) have discussed the difficulties involved in comparing disease status between countries given the variety of codes. In the present study, the design of the recording sheet and the insistence that recordings be made simultaneously in all Nordic countries were an attempt to overcome these difficulties. The completeness obtained in this study therefore offer a sound background against which it is possible to compare differences in 'true' disease occurrence in the four Nordic countries (when national database data are adjusted with the completeness figures obtained here).

The decision to select herds of at least 15 cows represented a compromise between the four countries, which had very different typical herd sizes. The smallest farms, especially in NO and FIN, were removed from the target population. Opportunities to obtain disease recordings from such small farms would have been very limited, as they have very few disease cases per year. In DK the sample population would only have changed minimally without this selection criterion, because only 22 Danish herds $(0.55 \%)$ had fewer than 15 cows at the time of sampling. When herds are compared - whether within or between countries - a 'cluster effect' of herds, or cows, or regions, may arise. However, the magnitude of this clustering would be minor. It would not be feasible to adjust for it. Clustering is unlikely to have influenced the results presented here, since there were many study herds and the number of registered cases per herd was low. In addition these numbers will be lower when we only look at those farmer recorded events that matched with an event in the national database. 
The fact that observations in this study were a diagnostic event, not an individual animal also makes a difference to the thinking around clustering.

SE invited participation from a smaller sample of herds and then contacted non-responders. As a result SE had a better response rate than the other countries. For practical reasons, including time limitations, this sampling strategy could not be adopted in DK. In a study like this, where highly motivated farmers are crucial, the low response rate this inevitably entailed was felt to be acceptable. Other studies in which farmer participation was crucial to data collection have used inclusion criteria aimed to eliminate poor responders (Olsson et al., 1993; Ortman and Svensson, 2004). As farmers only seldom make the recordings to the database themselves, poor farmer recording is considered of minor importance and therefore no screening of eligible farmers to exclude poor reporters was performed. We thereby did not reduce the risk of bias stemming from poor reporting. On the other hand, nor did we increase the risk of bias arising from the inclusion only of farmers with good record keeping. Instead a great deal of effort was put into contacting and reminding individual farmers, and into follow-ups on any questions and/or problems they might have had during the recording period. In a prospective data collection study Bartlett et al. (1986) once claimed that since only farmers with adequate record-keeping can participate in data collection, some selection bias is inevitable. The completeness obtained in this study is highly dependent upon how well the farmers performed. Farmers who recorded too much (e.g. including subclinical diseases) or too little (e.g. including only those cases registered in the ND) could have affected the completeness obtained. Again, considerable efforts were made both to provide farmers with clear instructions on the method of recording and to ensure that farmers knew they should not record any more than they normally detected. However, it is true that the increase in completeness obtained when adjusting to F2 indicates that the farmers did not record all disease events.

\subsection{Representativeness of study herds}

The representativeness of the participating herds in the four Nordic countries was evaluated. There were only minimal differences between study herd and national population in DK and target population in FIN, NO and SE, and therefore the study herds were represented. In DK the study population could not be compared with the target population, because it was impossible to obtain data on the target population alone. However, the target population was almost the same as the national population in DK, because there were only 22 Danish herds with fewer than 15 cows per year, and these were removed from the DK sample.

DK had more withdrawn herds than the other countries. This was only to be expected, given the substantial workload associated with recording all disease events over a 4-month period in a country with bigger herds than the others. The sizeable workload may also explain the fact that DK was the only country in which participating farmers had smaller herd sizes than the country average. It can also be speculated that the greater workload required to record disease in larger herds might have led to underreporting, but since SE and DK are the countries with the largest herds, and since these two countries had the highest and lowest completeness, underreporting in large herds (by the Danish farmers) is unlikely to explain the differences in completeness for locomotor disorders.

\section{Conclusion}

In all four Nordic countries, the occurrence of locomotor disorders was documented at a low frequency. The completeness calculated was in the range of $0.12-0.22$ at FARMER level in the four countries. At this level, the adjusted gold standard (in which cases not recorded by the farmer but recorded in the national database are added) increased completeness in the range from 0.20 to 0.45 . The completeness was in the range from 0.17 to 0.37 at VET level. At this level, the adjusted gold standard (again, in which cases not recorded by the farmer but recorded in the national database are added) increased completeness from 0.26 to 0.64 . The completeness figures obtained for locomotor disorders differed between DK and SE, and between FIN and SE, when the sample was adjusted for non-farmer-recorded disease events recorded in the national database. This indicates that the comparison of incidences of locomotor diseases in different countries is far from straightforward.

\section{Conflict of interest}

The authors declare that the work could not have been inappropriately influenced of any financial or personal relationships with other people or organizations.

\section{Acknowledgements}

Access to data used in this study was given by the Danish Cattle Federation, the Finnish Agricultural Data Processing Centre Ltd, the Norwegian Dairy Herd Recording System (NDHRS) and the Norwegian Cattle Health Services (NCHS) according to agreement number 004.2007, and the Swedish Dairy Association.

The study was supported financially by grants from the Nordic Joint Committee for Agricultural research (NKJ) via the Danish Agency for Science Technology and Innovation, the Ministry of Agriculture and Forestry in Finland, the Research Council of Norway, and the Swedish Research Council Formas. Funding was also provided by the Danish Agriculture \& Food Council, Cattle and TINE SA.

The farmers who participated played a vital role in this research, and the authors are grateful for their contribution. The authors thank Mette Holme, Frøydis Hardeng, Jonna Oravainen and the Norwegian breeding and AI association (Geno). Thanks also to all the other participants in the research group; and especially to Anna-Maija Virtala, Agneta Egenvall, Ulf Emanuelson, Olav Østerås, Olav Reksen, Ann Lindberg, Juhani Taponen and Olli Peltoniemi, for valuable comments and input at all stages of the research. 


\section{References}

Anonymous, 2008. Helsekort Klauv. http://storfehelse.tine.no/ page?id=150.

Anonymous, 2009. Figures on Danish cattle. Danish Cattle Federation.

Anonymous, 2010. Sundhedsrådgivningsaftaler for kvæg. http:// www.foedevarestyrelsen.dk/Dyr/Dyresundhed_og_dyresygdomme/ Sundhedsraadgivning/Kvaeg/Forside.aspx.

Bartlett, P.C., Agger, J.F., Houe, H., Lawson, L.G., 2001. Incidence of clinical mastitis in Danish dairy cattle and screening for non-reporting in a passively collected national surveillance system. Prev. Vet. Med. 48, 73-83.

Bartlett, P.C., Kaneene, J.B., Kirk, J.H., Wilke, M.A., Martenuik, J.V., 1986. Development of a computerized dairy herd health data base for epidemiologic research. Prev. Vet. Med. 4, 3-14.

Bennedsgaard, T.W., 2003. Reduced use of veterinary drugs in organic dairy herds - Potentials and consequences. Ph.D. Thesis. The Royal Veterinary and Agricultural University, Frederiksberg, Denmark.

Casella, G., Berger, R.L., 1990. Statistical Inference. Duxbury Press, Belmont, CA, USA.

Egenvall, A., Bonnett, B.N., Olson, P., Hedhammar, A., 1998. Validation of computerized Swedish dog and cat insurance data against veterinary practice records. Prev. Vet. Med. 36, 51-65.

Egenvall, A., Nødtvedt, A., Roepstorff, L., Bonnett, B., 2011. Integrating databases for research on health and performance in small animals and horses in the Nordic countries. Acta Vet. Scand. 53, S4

Espetvedt, M.N., Wolff, C., Rintakoski, S., Lind, A., Østerås, O., 2012. Completeness of metabolic disease recordings in Nordic national databases for dairy cows. Prev. Vet. Med. 105, 25-37.

Gröhn, Y., Saloniemi, H., Syväjärvi, J., 1986. An epidemiological and genetic study on registered diseases in Finnish Ayrshire cattle: I. The data, disease occurrence and culling. Acta Vet. Scand. 27, $182-195$.

Gröhn, Y., Thompson, J.R., Bruss, M.L., 1984. Epidemiology and genetic basis of ketosis in Finnish Ayrshire cattle. Prev. Vet. Med. 3, 65-77.

Gulliksen, S.M., Lie, K.I., Løken, T., Østerås, 2009. Calf mortality in Norwegian dairy herds. J. Dairy Sci. 92, 2782-2795.

Houe, H., Gardner, I., Nielsen, L., 2011. Use of information on disease diagnoses from databases for animal health economic, welfare and food safety purposes: strengths and limitations of recordings. Acta Vet. Scand. 53, S7.

Jordan, K., Porcheret, M., Croft, P., 2004. Quality of morbidity coding in general practice computerized medical records: a systematic review. Fam. Pract. 21, 396-412.

Lindberg, A., Valde, J.P., Lawson, L., Saloniemi, H., Agger, J.F., Østerås, O., 2003. A quantitative approach to assessing the validity of national cattle disease recording systems in the Nordic countries. In: Proceeding of the 10th International Symposium on Veterinary Epidemiology and Economics.

Mörk, M., Lindberg, A., Alenius, S., Vagsholm, I., Egenvall, A., 2009. Comparison between dairy cow disease incidence in data registered by farmers and in data from a disease-recording system based on veterinary reporting. Prev. Vet. Med. 88, 298-307.

Mörk, M.J., Wolff, C., Lindberg, A., Vagsholm, I., Egenvall, A., 2010. Validation of a national disease recording system for dairy cattle against veterinary practice records. Prev. Vet. Med. 93, 183-192.

Olsson, S.O., Baekbo, P., Hansson, S.O., Rautala, H., Østeras, O., 2001. Disease recording systems and herd health schemes for production diseases. Acta Vet. Scand (Suppl. 94), 51-60.

Olsson, S.O., Viring, S., Emanuelsson, U., Jacobsson, S.O., 1993. Calf diseases and mortality in Swedish dairy herds. Acta Vet. Scand. 34, 263-269.

Ortman, K., Svensson, C., 2004. Use of antimicrobial drugs in Swedish dairy calves and replacement heifers. Vet. Rec. 154, 136-140.

Østerås, O., Solbu, H., Refsdal, A.O., Roalkvam, T., Filseth, O., Minsaas, A., 2007. Results and evaluation of thirty years of health recordings in the Norwegian dairy cattle population. J. Dairy Sci. 90, 4483-4497.

Østerås, O., Valde, J.P., Lindberg, A., Lawson, L., Saloniemi, H., Agger, J.F., 2002. Disease incidence in dairy cows in Nordic countries-comparison of national disease reporting systems. Final Scientific Report, NKJ 1.276.

Østerås, O., Valde, J.P., Saloniemi, H., Lindberg, A., Lawson, L., Agger, J.F., 2003. Differences in disease treatment risks in the Nordic countries. In: Proceeding of the 10th International Symposium on Veterinary Epidemiology and Economics.

Penell, J.C., Bonnett, B.N., Pringle, J., Egenvall, A., 2009. Validation of computerized diagnostic information in a clinical database from a national equine clinic network. Acta Vet. Scand., 51.

Penell, J.C., Egenvall, A., Bonnett, B.N., Pringle, J., 2007. Validation of computerized Swedish horse insurance data against veterinary clinical records. Prev. Vet. Med. 82, 236-251.

Plym-Forshell, K., Østerås, O., Aagard, K., Kulkas, L., 1995. Disease recording and cell count data in 1993 in Sweden, Norway Denmark and Finland. In: Proceedings of the 3rd International Mastitis Seminar, 28 May-June 1, 1995, Tel Aviv, Israel.

Sørensen, H., Sabroe, S., Olsen, J., 1996. A framework for evaluation of secondary data sources for epidemiological research. Int. J. Epidemiol. $25,435-442$.

Sviland, S., Waage, S., 2002. Clinical bovine mastitis in Norway. Prev. Vet. Med. 54, 65-78.

Vaarst, M., Paarup-Laursen, B., Houe, H., Fossing, C., Andersen, H.J., 2002. Farmers' choice of medical treatment of mastitis in danish dairy herds based on qualitative research interviews. J. Dairy Sci. 85 (4), 992-1001.

Valde, J.P., Lawson, L.G., Lindberg, A., Agger, J.F., Saloniemi, H., Østeras, O., 2004. Cumulative risk of bovine mastitis treatments in Denmark, Finland, Norway and Sweden. Acta Vet. Scand. 45, 201-210. 